\title{
Malo kompleksne analize i osnovni teorem algebre
}

\author{
Ljiljana Arambašić, Maja Horvat
}

\section{Sažetak}

Cilj je ovog rada približiti neke osnovne pojmove i teoreme iz kompleksne analize. Kako nam je svima poznat osnovni teorem algebre, dat ćemo dva njegova dokaza koji se baziraju na teoremima iz kompleksne analize.

Ključni pojmovi: kompleksni brojevi, kompleksne funkcije, osnovni teorem algebre

\section{Uvod}

Studenti nastavničkog smjera preddiplomskog studija matematike na trećoj godini imaju mogućnost, između nekoliko ponuđenih, izabrati kolegij Kompleksna analiza. Kompleksna analiza se bavi proučavanjem kompleksnih funkcija kompleksne varijable, dakle, funkcija $f: \Omega \rightarrow \mathbb{C}$, pri čemu je $\Omega$ podskup od $\mathbb{C}$. Proučavamo ih na slične načine kako to radimo i s realnim funkcijama realne varijable. Dakle, tražimo nultočke, domenu, sliku funkcije, provjeravamo ograničenost, neprekidnost, derivabilnost, računamo integrale po putovima, tražimo primitivne funkcije te diskutiramo ostale slične koncepte za koje su studenti već čuli u ranijim kolegijima diferencijalnog i integralnog računa realnih funkcija.

Iako kolegij, pa čak i ovaj uvod, obiluju riječju „kompleksan”, sam kolegij nije (ili bar ne bi trebao biti) jako težak. Cilj ovog članka je prezentirati nekoliko zanimljivih tvrdnji iz kompleksne analize i njihove 
posljedice. Dokaze tvrdnji ćemo uglavnom skicirati, to jest, dati osnovne ideje.

\section{Graf kompleksne funkcije kompleksne va- rijable}

U proučavanju svojstava realnih funkcija realne varijable vrlo često koristimo graf funkcije. Kako su domena i kodomena realnih funkcija realne varijable jednodimenzionalne ( $\mathrm{tj}$. treba nam jedna os za domenu i jedna za kodomenu), grafove ovih funkcija crtamo u ravnini. Slično, ako imamo realne funkcije dviju realnih varijabli, dakle funkcije čija je domena podskup od $\mathbb{R}^{2}$ i kodomena $\mathbb{R}$, onda graf crtamo u trodimenzionalnom koordinatnom sustavu.

Kod kompleksnih funkcija kompleksne varijable stvar je kompliciranija, s obzirom da nam već za prikaz kompleksnih brojeva treba ravnina, pa bismo onda za njihove grafove trebali četiri dimenzije.

Jedan način za prikaz ovakvih funkcija je korištenje boja. Srećom, prolaskom kroz cijeli spektar imat ćemo „dovoljno” različitih boja, odnosno nijansi boja, kako bismo različitim točkama ravnine mogli pridružiti različite boje (injektivnost funkcije koja točki ravnine pridružuje boju). Dakle, svakom broju u kompleksnoj ravnini pridružujemo boju i ta ga boja jednoznačno određuje. Na sljedećoj je slici prikazana kompleksna ravnina u kojoj su točkama dodijeljene različite boje.

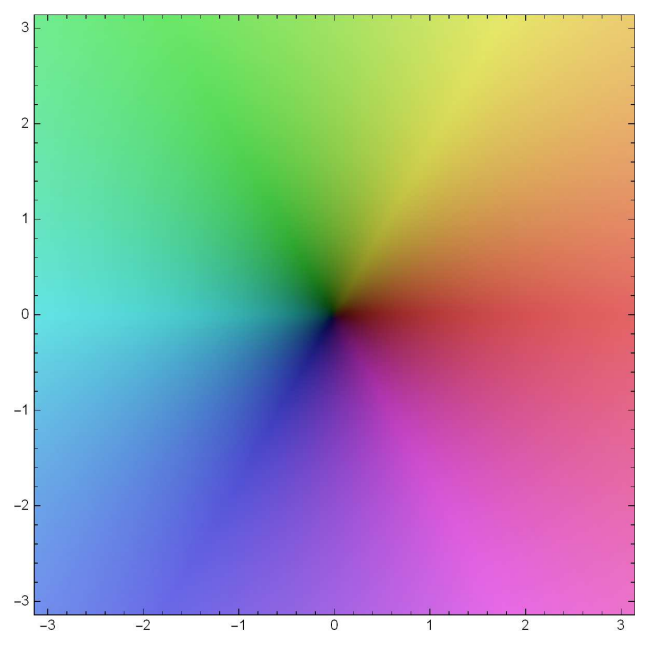

Slika 1 
Ishodište je obojeno crnom bojom. Obilazeći oko ishodišta u smjeru suprotnom kretanju kazaljke na satu, prolazimo bojama spektra: crvenom, narančastom, žutom, zelenom, plavom, modrom i ljubičastom. Kada se kompleksan broj $z$ približava nuli, boja pridružena tom broju postaje sve tamnija i približava se crnoj. Boja pridružena kompleksnom broju $z$ kada $|z|$ teži u beskonačnost postaje sve svjetlija i približava se bijeloj. Na opisani smo način svakom kompleksnom broju pridružili različitu boju i tako je svaki kompleksan broj jednoznačno određen bojom koja je na to mjesto ravnine postavljena.

$\mathrm{Na}$ sljedećoj je slici prikazana funkcija $f(z)=z^{2}$. S obzirom da se $\operatorname{broj} z=|z|(\cos \varphi+i \sin \varphi)$ kvadriranjem preslikava $\mathrm{u} z^{2}=|z|^{2}(\cos 2 \varphi+$ $i \sin 2 \varphi$ ), zaključujemo da će se spektar boja dva puta namotati oko ishodišta, boje unutar jediničnog kruga će, krenuvši od kružnice prema ishodištu, brže tamniti u odnosu na prvu sliku (jer $|z|^{2}<|z|$ za $|z|<1$ ), dok će boje izvan jediničnog kruga, krenuvši od kružnice prema „beskonačnosti", brže gubiti intenzitet u odnosu na prvu sliku (jer $|z|^{2}>|z|$ za $|z|>1)$.

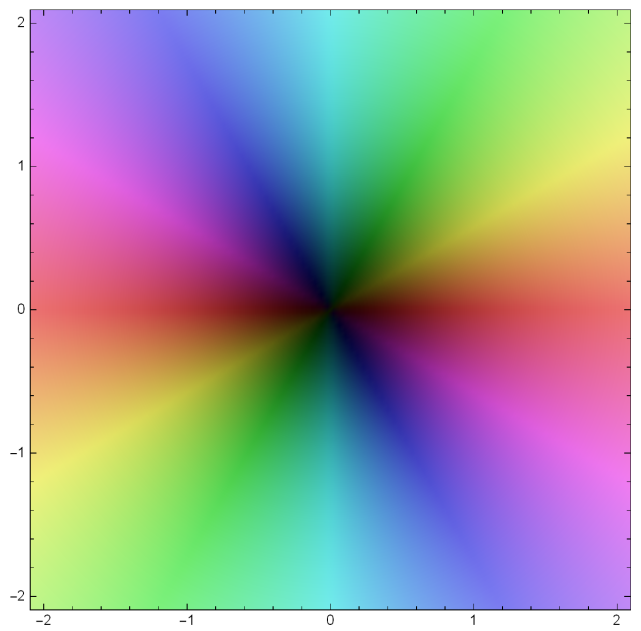

Slika 2

Prethodne slike nacrtane su koristeći Mathematicu. Također, na stranici http://jutanium.github.io/ComplexNumberGrapher dostupna je aplikacija za ovakav prikaz kompleksnih funkcija.

\section{$3 \quad$ Elementarne funkcije}

Jasno je što su kompleksni polinomi ili kompleksne racionalne funkcije. 
Polinom stupnja $n$ je funkcija $p: \mathbb{C} \rightarrow \mathbb{C}$ oblika

$$
p(z)=a_{n} z^{n}+a_{n-1} z^{n-1}+\cdots+a_{1} z+a_{0},
$$

gdje su $a_{0}, a_{1}, \ldots, a_{n}$ kompleksni brojevi, $a_{n} \neq 0$. Na primjer, funkcija $p(z)=z^{3}-(3+i) z+12$ je (kompleksni) polinom trećeg stupnja.

Racionalna funkcija $r$ je funkcija oblika

$$
r(z)=\frac{p(z)}{q(z)}
$$

gdje su $p$ i $q$ polinomi i $q$ nije nul-polinom. Prirodna domena racionalne funkcije $r$ je skup $\Omega=\{z \in \mathbb{C}: q(z) \neq 0\}$. Na primjer, funkcija

$$
r(z)=\frac{z^{3}-3 z+12}{z^{2}+1}
$$

je jedna racionalna funkcija. Njena prirodna domena je

$$
\Omega=\left\{z \in \mathbb{C}: z^{2}+1 \neq 0\right\}=\mathbb{C} \backslash\{ \pm i\} .
$$

Važnu ulogu u realnoj analizi imaju eksponencijalne, logaritamske i trigonometrijske funkcije. Možemo li i kako definirati kompleksne funkcije ovih vrsta?

Kompleksnu eksponencijalnu funkciju kompleksne varijable definiramo kao funkciju

$$
\exp : \mathbb{C} \rightarrow \mathbb{C}, \quad \exp (z)=\exp (x+i y)=e^{x}(\cos y+i \sin y) .
$$

S obzirom da je $\mathbb{R} \subseteq \mathbb{C}$, bitno je da funkcija exp proširuje realnu eksponencijalnu funkciju $f: \mathbb{R} \rightarrow \mathbb{R}, f(x)=e^{x}$. To je zaista tako, jer ako uvrstimo $y=0 \mathrm{u}$ gornju formulu, dobit ćemo $\exp (x)=e^{x}$. Pokazuje se, nadalje, da vrijede svojstva koja poznajemo iz realnog slučaja, na primjer,

$$
e^{z+w}=e^{z} e^{w}, \quad \frac{1}{e^{z}}=e^{-z}, \quad z, w \in \mathbb{C},
$$

i sve to nam opravdava način kako smo eksponencijalnu funkciju definirali.

Kompleksna eksponencijalna funkcija je periodična perioda $2 \pi i$, jer za sve $z \in \mathbb{C}$ vrijedi

$$
\begin{aligned}
e^{z+2 \pi i} & =e^{x+i(y+2 \pi)}=e^{x}(\cos (y+2 \pi)+i \sin (y+2 \pi)) \\
& =e^{x}(\cos y+i \sin y)=e^{z} .
\end{aligned}
$$

Na slici je njen prikaz pomoću boja. 


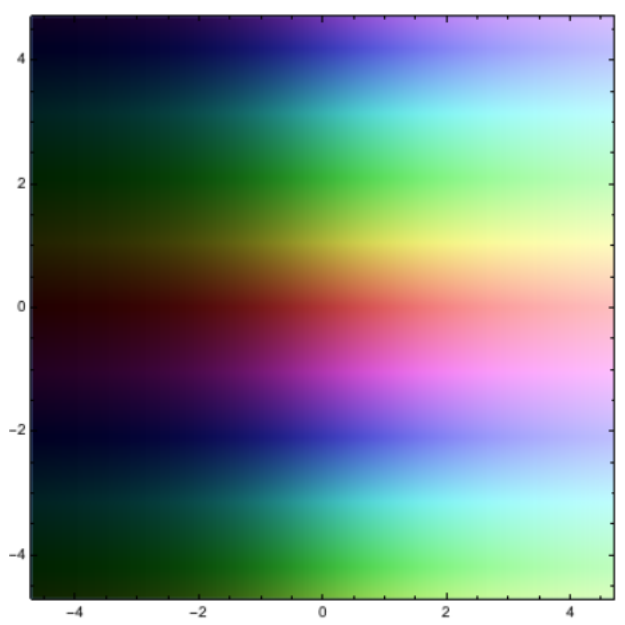

Slika 3

Iz periodičnosti slijedi da kompleksna eksponencijalna funkcija nije bijekcija, te zato ne postoji njena inverzna funkcija. Kao što znamo, u realnom slučaju se logaritamske funkcije definiraju kao inverzne funkcije eksponencijalnih funkcija. Kako bi se ipak konstruirala kompleksna logaritamska funkcija, promatra se restrikcija eksponencijalne funkcije na domenu na kojoj je ova funkcija injektivna, te kodomenu biramo tako da je ta restrikcija i surjektivna; tako imamo bijektivnost i možemo definirati inverznu funkciju. U ovom članku nećemo iznositi detalje o tome.

Napomenimo još samo da se kompleksne trigonometrijske funkcije definiraju pomoću kompleksne eksponencijalne funkcije formulama

$$
\sin z=\frac{e^{i z}-e^{-i z}}{2 i}, \quad \cos z=\frac{e^{i z}+e^{-i z}}{2}
$$

za sve $z \in \mathbb{C}$. Ove funkcije proširuju realne funkcije sinusa i kosinusa $\mathrm{i}$ imaju svojstva poput svojih realnih varijanti.

\section{Derivacija}

Kao i kod realnih funkcija realne varijable pojam derivacije definira se pomoću limesa. Točnije, kažemo da je funkcija $f$ derivabilna u točki $z_{0}$ iz svoje domene ako postoji

$$
\lim _{z \rightarrow z_{0}} \frac{f(z)-f\left(z_{0}\right)}{z-z_{0}}
$$


U tom slučaju taj limes označavamo s $f^{\prime}\left(z_{0}\right)$ i nazivamo derivacija funkcije $f$ u točki $z_{0}$.

Pokazuje se da vrijede ista pravila za deriviranje kao i u realnom slučaju (npr. pravilo za deriviranje produkta ili kompozicije funkcija). Drugim riječima, kompleksne funkcije deriviramo točno onako kako smo naučili derivirati realne funkcije. Tako je, na primjer, $\left(z^{2}\right)^{\prime}=2 z$, baš kao što je i derivacija realne funkcije $\left(x^{2}\right)^{\prime}=2 x$. Vrijedi $\left(e^{z}\right)^{\prime}=e^{z},(\sin z)^{\prime}=$ $\cos z,(\cos z)^{\prime}=-\sin z$, baš kako smo i očekivali.

Provjerimo i derivabilnost još jedne vrlo jednostavne funkcije: $f(z)=$ Re z. Pretpostavimo da postoji

$$
\lim _{z \rightarrow z_{0}} \frac{\operatorname{Re} z-\operatorname{Re} z_{0}}{z-z_{0}} .
$$

Neka je $z_{0}=x_{0}+i y_{0}$. Tada, promatramo li razne načine kako $z$ teži $u$ $z_{0}$, svaki od tih načina treba dati istu vrijednost limesa. Međutim, ako je $z=x+i y_{0}$ i $x$ teži prema $x_{0}$ (to jest, $z$ je na pravcu kroz $z_{0}$ koji je paralelan realnoj osi i približava se $z_{0}$ ), tada dobivamo

$$
\lim _{z \rightarrow z_{0}} \frac{\operatorname{Re} z-\operatorname{Re} z_{0}}{z-z_{0}}=\lim _{x \rightarrow x_{0}} \frac{x-x_{0}}{\left(x+i y_{0}\right)-\left(x_{0}+i y_{0}\right)}=1
$$

S druge strane, ako je $z=x_{0}+i y$ i $y$ teži prema $y_{0}$ (to jest, $z$ je na pravcu kroz $z_{0}$ koji je paralelan imaginarnoj osi i približava se $z_{0}$ ), tada dobivamo

$$
\lim _{z \rightarrow z_{0}} \frac{\operatorname{Re} z-\operatorname{Re} z_{0}}{z-z_{0}}=\lim _{y \rightarrow y_{0}} \frac{x_{0}-x_{0}}{\left(x_{0}+i y\right)-\left(x_{0}+i y_{0}\right)}=0 .
$$

To nas dovodi do kontradikcije s pretpostavkom, a onda i zaključka da ovaj limes ne postoji, odosno da $f(z)=\operatorname{Re} z$ nije derivabilna funkcija niti u jednoj točki.

\section{Cauchy-Riemannovi uvjeti}

Prvo svojstvo derivabilnih kompleksnih funkcija kompleksne varijable istražit ćemo na jednom jednostavnom primjeru.

Pogledajmo funkciju $f(z)=z^{3}$. Možemo napisati

$$
f(x+i y)=(x+i y)^{3}=\left(x^{3}-3 x y^{2}\right)+i\left(3 x^{2} y-y^{3}\right) .
$$

Označimo

$$
u(x, y)=x^{3}-3 x y^{2}, \quad v(x, y)=3 x^{2} y-y^{3}
$$


Ove funkcije nazivamo realni i imaginarni dio funkcije $f$ i to su funkcije koje ovise i o $x$ i o $y$. Ako na trenutak zamislimo da je $x$ u prethodnim formulama konstanta, a $y$ varijabla, te funkcije $u$ i $v$ deriviramo po varijabli $y$, tada dobivamo izraze $-6 x y$ i $3 x^{2}-3 y^{2}$. Dobiveni izrazi predstavljaju parcijalne derivacije funkcija $u$ i $v$ po $y$, i obično ih označavamo s $u_{y}^{\prime}$ i $v_{y}^{\prime}$.

Ako sad promijenimo uloge $x$ i $y$, to jest, ako sada zamišljamo da je $y$ konstanta, a $x$ varijabla, nakon deriviranja (po $x$ ) dobit ćemo izraze $3 x^{2}-3 y^{2}$ i $6 x y$. Dobivene izraze označavamo s $u_{x}^{\prime}$ i $v_{x}^{\prime}$ i nazivamo parcijalne derivacije funkcija $u$ i $v$ po $x$. Očito je da vrijedi

$$
u_{x}^{\prime}=v_{y}^{\prime}, \quad u_{y}^{\prime}=-v_{x}^{\prime} .
$$

Možemo pomisliti da se radi o slučajnosti, to jest, o specifičnosti odabrane funkcije, međutim, ako bismo postupak ponovili za npr. bilo koju potenciju ili eksponencijalnu funkciju, dobili bismo isti zaključak; dakle, vjerojatno nije slučajnost, nego pravilo. Zaista, može se dokazati da svaka derivabilna funkcija zadovoljava relacije (1), koje nazivamo CauchyRiemannovi uvjeti. Napomenimo još i da su, uz pretpostavku da parcijalne derivacije $u_{x}^{\prime}, u_{y}^{\prime}, v_{x}^{\prime}, v_{y}^{\prime}$ postoje i da su neprekidne, CauchyRiemannovi uvjeti i dovoljni za derivabilnost funkcije $f$.

Pogledajmo još jednom primjer funkcije $f(z)=\operatorname{Re} z$ za koju smo maloprije ustanovili da nije derivabilna. Ovdje je $u(x, y)=x$ i $v(x, y)=$ 0 , pa se lako provjeri da Cauchy-Riemannovi uvjeti nisu ispunjeni i zato ova funkcija nije derivabilna.

\section{Liouvilleov teorem}

Liouvilleov teorem je jedan od zanimljivijih teorema koji vrijede $\mathrm{u}$ kompleksnoj analizi i odnosi se na cijele funkcije, to jest, funkcije čija je domena $\mathbb{C}$ i koje su derivabilne u svakoj točki iz $\mathbb{C}$.

Spomenimo da je kompleksna funkcija $f: \Omega \rightarrow \mathbb{C}$ ograničena ako postoji $M>0$ tako da je $|f(z)| \leq M$ za sve $z \in \Omega$.

Liouvilleov teorem. Ako je $f$ cijela $i$ ograničena funkcija, onda je $f$ konstantna funkcija.

Naravno, analogon ovog teorema ne vrijedi u realnom slučaju, npr funkcija $\sin : \mathbb{R} \rightarrow \mathbb{R}$ je ograničena i svuda derivabilna, ali nije konstantna. Također, odmah možemo zaključiti da kompleksne funkcije sin i cos nisu ograničene na $\mathbb{C}$; naime, kako su one cijele funkcije, kada bi bile ograničene, onda bi Liouvilleov teorem dao da su konstantne, što nisu.

Jedna od posljedica Liouvilleovog teorema je i osnovni teorem algebre. 
Osnovni teorem algebre. Svaki polinom stupnja $n \geq 1$ ima točno $n$ nultočaka u $\mathbb{C}$, ako pritom brojimo kratnosti tih nultočaka.

Dokaz. Pretpostavimo da je $p$ polinom koji nema nultočke, dakle, $p(z) \neq$ 0 za svaki $z \in \mathbb{C}$. Tada je dobro definirana sljedeća funkcija

$$
f: \mathbb{C} \rightarrow \mathbb{C}, \quad f(z)=\frac{1}{p(z)} .
$$

Ovo je cijela funkcija, jer je kvocijent dviju derivabilnih funkcija.

Kako $|p(z)|$ teži u $\infty$ kada $z$ teži u $\infty$, zaključujemo da $|f(z)|$ teži u 0 kada $z$ teži u $\infty$. Dakle, ako se udaljimo dovoljno od ishodišta, recimo barem za neki $R, f$ će poprimati male vrijednosti. Drugim riječima, na tom dijelu $f$ će biti ograničena funkcija.

Ostaje vidjeti što se događa na onom dijelu koji „nije dovoljno daleko" od ishodišta, to jest na krugu $K=\{z \in \mathbb{C}:|z| \leq R\}$. Kako su sve neprekidne kompleksne funkcije na zatvorenim omeđenim skupovima ograničene, slijedi da je i funkcija $f$ ograničena na skupu $K$.

Sada imamo da je $f$ ograničena i izvan i unutar $K$, pa slijedi da je $f$ cijela funkcija i ograničena na $\mathbb{C}$ i zato nužno konstanta. Ali tada je i $p$ konstanta, što ne može biti, budući je $p$ polinom stupnja barem 1 . To znači da se početna pretpostavka, to jest da $p$ nema nultočaka, ne može dogoditi.

Time smo dokazali da svaki polinom ima barem jednu nultočku. Neka je to $z_{1} \in \mathbb{C}$. Tada, koristeći Bezoutov teorem, imamo $p(z)=\left(z-z_{1}\right) q(z)$, gdje je $q$ polinom stupnja $n-1$. Ako je $q$ konstantni polinom, onda smo gotovi, a ako je stupanj od $q$ barem 1 , tada $q$ također ima barem jednu nultočku u $\mathbb{C}$, što je ujedno nultočka od $p$, i ponavljajući postupak dolazimo do tvrdnje teorema.

\section{$7 \quad$ Picardov teorem}

Iako nam već i tvrdnja Liouvilleovog teorema može biti iznenađujuća (u usporedbi s realnim slučajem), sljedeći teorem govori još više od toga.

Picardov teorem. Neka je $f$ nekonstantna cijela funkcija. Tada je njena slika ili cijeli $\mathbb{C}$ ili $\mathbb{C}$ bez jedne točke.

Prema Liouvilleovom teoremu, ako se sve vrijednosti cijele funkcije $f$ nalaze unutar nekog kruga, to jest, ako funkcija $f$ ne poprima niti jednu vrijednost izvan tog kruga, onda je $f$ konstantna funkcija. Picardov teorem daje isti zaključak o cijeloj funkciji uz slabiju pretpostavku: čim cijela funkcija ne poprimi neke dvije vrijednosti u $\mathbb{C}$, ona je konstantna funkcija. 
Polinomi stupnja barem 1 su cijele nekonstantne funkcije. Prema Picardovom teoremu, slika polinoma je $\mathbb{C}$ ili $\mathbb{C} \backslash\{w\}$ za neki $w \in \mathbb{C}$. Međutim, prema osnovnom teoremu algebre, ako je $p$ polinom stupnja barem 1 , onda jednadžba $p(z)=w$ ima rješenje za svaki $w \in \mathbb{C}$. To znači da je slika od $p$ jednaka $\mathbb{C}$.

Također, exp je cijela nekonstantna funkcija. Uočimo da je $e^{z} \neq 0$ za sve $z \in \mathbb{C}$; naime, kada bi postojao $z=x+i y$ takav da je $e^{x}(\cos y+$ $i \sin y)=0$ tada bi slijedilo $\cos y=\sin y=0$, što nije moguće. Prema tome, $\mathrm{u}$ slici funkcije exp se ne nalazi 0 , a onda prema Picardovom teoremu slijedi da se sve druge kompleksne vrijednosti nalaze u toj slici, odnosno da je slika kompleksne eksponencijalne funkcije $\mathbb{C} \backslash\{0\}$.

Za kraj članka navodimo dokaz osnovnog teorema algebre preko Picardovog teorema (vidi [1]), te opisujemo kako iz osnovnog teorema algebre slijedi faktorizacija polinoma.

Još jedan dokaz osnovnog teorema algebre. Neka je $p$ polinom s kompleksnim koeficijentima stupnja barem 1. Pretpostavimo da je $p(z) \neq 0$ za svaki $z \in \mathbb{C}$.

Budući da je $p$ nekonstantna cijela funkcija i da ne postiže vrijednost 0 , prema Picardovom teoremu $p$ mora postizati sve kompleksne vrijednosti različite od 0 . Posebno, $p$ postiže sve vrijednosti $\frac{1}{n}$ za sve $n \in \mathbb{N}$, dakle, možemo naći točke $z_{n} \in \mathbb{C}$ takve da vrijedi $p\left(z_{n}\right)=\frac{1}{n}, n \in \mathbb{N}$. Kako je

$$
\lim _{|z| \rightarrow \infty}|p(z)|=\infty
$$

slijedi da, za sve točke koje su dovoljno udaljene od ishodišta, recimo barem za neki $R$, vrijedi $|p(z)|>1$. Kako je $\left|p\left(z_{n}\right)\right| \leq 1$ za sve $n$, to se cijeli niz $\left(z_{n}\right)$ nalazi unutar zatvorenog kruga oko ishodišta radijusa $R$, prema tome, taj niz je ograničen.

Poznato je da svaki ograničen niz ima konvergentan podniz. Zato postoji podniz $\left(z_{n_{k}}\right)$ koji konvergira prema nekoj točki $z_{0}$. Zbog neprekidnosti od $p$, niz $\left(p\left(z_{n_{k}}\right)\right)$ konvergira prema $p\left(z_{0}\right)$, pa imamo

$$
p\left(z_{0}\right)=\lim _{k \rightarrow \infty} p\left(z_{n_{k}}\right)=\lim _{k \rightarrow \infty} \frac{1}{n_{k}}=0,
$$

to jest, $z_{0}$ je nultočka od $p$. To je suprotno pretpostavci da ne postoji nultočka, pa je ta pretpostavka (o nepostojanju nultočaka) pogrešna. Do ostalih nultočaka od $p$ dolazimo kao u prethodnom dokazu.

Neka je $p$ polinom stupnja $n$ i $a_{n}$ njegov vodeći koeficijent. Ako je $z_{1}$ nultočka od $p$, tada je $p(z)=q_{1}(z)\left(z-z_{1}\right)$ za neki polinom $q_{1}$ stupnja $n-1$. Ako je $z_{1}$ višestruka nultočka od $p$, onda je $z_{1}$ nultočka i od $q_{1}$, pa na isti način zaključimo da je $q_{1}$ djeljiv sa $z-z_{1}$, odakle slijedi da 
je $p(z)=\left(z-z_{1}\right)^{2} q_{2}(z)$ za neki polinom $q_{2}$ stupnja $n-2$. Analognim zaključivanjem dolazimo do sljedećeg rezultata: ako je $p$ polinom stupnja $n$ i $z_{1}, \ldots, z_{k}$ nultočke od $p$ kratnosti $r_{1}, \ldots, r_{k}$, tada je

$$
p(z)=a_{n}\left(z-z_{1}\right)^{r_{1}} \cdots\left(z-z_{k}\right)^{r_{k}},
$$

što predstavlja faktorizaciju polinoma $p$. Ovdje je osnovni teorem algebre bitan jer osigurava postojanje točaka $z_{1}, \ldots, z_{k}$, te da je $r_{1}+\ldots+r_{k}=n$.

\section{Literatura}

[1] A. A. Azzam, An eighth proof using Picard's Theorem, https://adamazzam.wordpress.com/2012/06/05/usingpicards-theorem-an-eighth-proof 2012.

[2] M. Horvat, Osnovni teorem algebre, diplomski rad, PMFMatematički odsjek, Sveučilište u Zagrebu, 2018. (mentor: Ljiljana Arambašić)

[3] Š. Ungar, Kompleksna analiza, https://web.math.pmf.unizg. hr/ ungar/kompleksna.pdf, 2009.

[4] D. Velleman, The Fundamental Theorem of Algebra: A Visual Approach, https://sites.math.washington.edu/ morrow/ 336_14/fta.pdf, 2012.

[5] Complex function grapher, http://jutanium.github.io/ ComplexNumberGrapher/

Ljiljana Arambašić

PMF-Matematički odsjek Sveučilišta u Zagrebu, Bijenička cesta 30, Zagreb

E-mail adresa: arambas@math.hr

Maja Horvat

Srednja škola Bedekovčina, Gajeva 1, Bedekovčina

E-mail adresa: maja.horvat.pmf@gmail.com 